(n)

\title{
Decreased glycolytic and tricarboxylic acid cycle intermediates coincide with peripheral nervous system oxidative stress in a murine model of type 2 diabetes
}

\section{Lucy M Hinder, Anuradha Vivekanandan-Giri', Lisa L McLean, Subramaniam Pennathur ${ }^{1}$ and Eva L Feldman}

Department of Neurology, University of Michigan, AATBSRB, 109 Zina Pitcher Place, Ann Arbor, Michigan 48109-2200, USA

'Department of Internal Medicine, University of Michigan, Ann Arbor, Michigan 48109, USA
Correspondence

should be addressed to

E L Feldman

Email

efeldman@med.umich.edu

\begin{abstract}
Diabetic neuropathy (DN) is the most common complication of diabetes and is characterized by distal-to-proximal loss of peripheral nerve axons. The idea of tissue-specific pathological alterations in energy metabolism in diabetic complications-prone tissues is emerging. Altered nerve metabolism in type 1 diabetes models is observed; however, therapeutic strategies based on these models offer limited efficacy to type 2 diabetic patients with DN. Therefore, understanding how peripheral nerves metabolically adapt to the unique type 2 diabetic environment is critical to develop disease-modifying treatments. In the current study, we utilized targeted liquid chromatography-tandem mass spectrometry (LC/MS/MS) to characterize the glycolytic and tricarboxylic acid (TCA) cycle metabolomes in sural nerve, sciatic nerve, and dorsal root ganglia (DRG) from male type 2 diabetic mice (BKS.Cg-m $+/+$ Lepr $^{\mathrm{db}} ; d b / d b$ ) and controls $(d b /+)$. We report depletion of glycolytic intermediates in diabetic sural nerve and sciatic nerve (glucose-6-phosphate, fructose-6-phosphate, fructose-1,6-bisphosphate (sural nerve only), 3-phosphoglycerate, 2-phosphoglycerate, phosphoenolpyruvate, and lactate), with no significant changes in DRG. Citrate and isocitrate TCA cycle intermediates were decreased in sural nerve, sciatic nerve, and DRG from diabetic mice. Utilizing LC/electrospray ionization/MS/MS and HPLC methods, we also observed increased protein and lipid oxidation (nitrotyrosine; hydroxyoctadecadienoic acids) in $d b / d b$ tissue, with a proximal-to-distal increase in oxidative stress, with associated decreased aconitase enzyme activity. We propose a preliminary model, whereby the greater change in metabolomic profile, increase in oxidative stress, and decrease in TCA cycle enzyme activity may cause distal peripheral nerves to rely on truncated TCA cycle metabolism in the type 2 diabetes environment.
\end{abstract}

\footnotetext{
Key Words

- diabetes

- neuropathy

- metabolomics

- sural nerve

- sciatic nerve

- dorsal root ganglia
}

Journal of Endocrinology (2013) 216, 1-11
(๑) 2013 Society for Endocrinology Printed in Great Britain
Published by Bioscientifica Ltd 


\section{Introduction}

According to statistics published by the Centers for Disease Control (2011), $\sim 8 \%$ of the US population has diabetes mellitus, with 1.9 million new cases diagnosed in 2010. Although both type 1 diabetes and type 2 diabetes are characterized by impaired insulin signaling and hyperglycemia, the two disease forms are distinct. Type 2 diabetes, accounting for 95\% of all cases (CDCP 2011), is a metabolic disease characterized by high pancreatic insulin production and insulin resistance in muscle, fat, and liver. The remaining 5\% of individuals have type 1 diabetes (CDCP 2011), which is characterized by autoimmune destruction of the pancreas and loss of insulin production.

Diabetic neuropathy (DN) is the most common complication of diabetes and over time affects $\sim 60 \%$ of all patients with the disease (Vincent \& Feldman 2004). DN is characterized by progressive, length-dependent loss of peripheral nerve axons in a stocking and glove (distal-toproximal) pattern (Said 2007), resulting in pain, decreased sensation, and eventually complete loss of sensation. In the USA, DN is the leading cause of diabetes-related hospital admissions and non-traumatic amputations (Edwards et al. 2008, Feldman 2008). Despite the morbidity associated with $\mathrm{DN}$, there is currently no treatment available to patients suffering from DN other than glycemic control, largely due to our incomplete understanding of disease mechanisms. In order to gain insight into $\mathrm{DN}$ pathogenesis and develop disease-modifying treatments, we have recently started to investigate the role of aberrant energy metabolism in the peripheral nervous system. We hypothesize that $\mathrm{DN}$ arises from tissue-specific metabolic reprogramming, resulting in alterations in fuel utilization that lead to dysfunction of the tissue.

Glucose is the major substrate for peripheral nerves, although they do not rely on insulin for its uptake (Greene \& Winegrad 1979). In rodent models of type 1 diabetes, peripheral nerve glucose content is elevated (Thurston et al. 1995, Kishi et al. 1999, Obrosova et al. 2005b) and oxidative stress is increased within the sciatic nerve and the dorsal root ganglia (DRG) containing the sensory neuron cell bodies (Vincent et al. 2004). It is also established that all mechanisms known to be contributory to the onset and progression of DN are in some way related to oxidative stress (Vincent et al. 2011). Based on the findings primarily in cultured endothelial cells, oxidative stress was thought to be related to hyperglycemia-induced overproduction of superoxide $\left(\mathrm{O}_{2}{ }^{-}\right)$by the mitochondrial electron transport chain (Brownlee 2001). Thus, it was proposed that increased glycolytic flux leads to increased hyperglycemia-derived electron donors from the tricarboxylic acid (TCA) cycle $\left(\mathrm{FADH}_{2}\right.$ and $\left.\mathrm{NADH}\right)$, which generates a high mitochondrial membrane potential, facilitating the reduction of $\mathrm{O}_{2}$ to $\mathrm{O}_{2}{ }^{-}$(Brownlee 2001, Tomlinson \& Gardiner 2008). Indeed, a study by Thurston et al. (1995) in the mid 1990s reported an increase in nerve glycolytic intermediates in long-term type 1 diabetes in rats. Recent reports, however, suggest downregulation of glycolytic intermediates in complication-prone tissues in type 1 diabetes, including peripheral nerves (Gardiner et al. 2007), retina (Ola et al. 2006), and lens (Obrosova \& Stevens 1999). Recent metabolomic studies in models of type 1 diabetes reported downregulation of key TCA cycle and mitochondrial proteins (Akude et al. 2011) and enzyme activities (Chowdhury et al. 2010) in DRG, with decreased mitochondrial $\mathrm{O}_{2}{ }^{-}-$production (Akude et al. 2011). Conversely, Schwann cells grown under hyperglycemic conditions demonstrated upregulation of the TCA cycle and mitochondrial proteins (Zhang et al. 2010). Critically, these data were produced in models of type 1 diabetes.

While the mechanisms underlying type 1 diabetes and type 2 diabetes are distinct, it is generally held that $\mathrm{DN}$ is due to hyperglycemic damage, regardless of the type of diabetes (Callaghan et al. 2012). However, DN is more common in patients with type 2 diabetes (Young et al. 1993), and DN in type 2 diabetic patients is less amenable to tight glycemic control, indicating differing underlying pathogenic mechanisms (Callaghan et al. 2012). Despite the significant progress in our understanding of altered peripheral nerve metabolism in models of type 1 diabetes, fundamental differences between type 1 diabetes and type 2 diabetes confer a critical need to understand how peripheral nerves adapt to the unique type 2 diabetic environment (hyperglycemia, hyperinsulinemia, and hyperlipidemia). We hypothesize that measures of oxidative stress are increased in a proximal-to-distal gradient in peripheral nerves in type 2 diabetes, consistent with DN pathogenesis. This will be reflected in a decrease in the glycolytic and TCA cycle metabolomes and related enzymes moving proximally to distally from the DRG to the sciatic nerve and its terminal branches, including the sural nerve.

In the current study, we utilized liquid chromatography-tandem mass spectrometry (LC/MS/MS) and LC-electrospray ionization (ESI)-MS/MS to explore glycolytic and TCA cycle metabolomic changes within sural nerve, sciatic nerve, and DRG of the BKS.Cg-m +/ Lepr ${ }^{\mathrm{db}}$

Published by Bioscientifica Ltd. 
$(\mathrm{db} / \mathrm{db})$ mouse model of type 2 diabetes. We present steady-state metabolomics data demonstrating decreased glycolytic intermediates in the sural and sciatic nerves and a decrease in TCA cycle intermediates in DRG, sciatic nerve, and sural nerve, complementing the published data in peripheral nerves in type 1 diabetes. We confirm that these changes occur concurrently with decreased aconitase enzyme activity as well as increased protein and lipid oxidation in the sciatic nerve and DRG. We present the first evidence that oxidative stress is more pronounced distally in peripheral nerves from a mouse model of type 2 DN. Finally, we propose a preliminary model whereby these changes may cause the sciatic nerve to rely on truncated TCA cycle metabolism in the type 2 diabetes environment.

\section{Materials and methods}

\section{Diabetic mice}

Male type 2 diabetic (BKS.Cg-m $+/+$ Lepr $^{\mathrm{db}} ; \mathrm{db} / \mathrm{db}$ ) and control $(\mathrm{db} /+)$ mice were purchased from Jackson Laboratories (Bar Harbor, ME, USA). A mutation in the leptin receptor of the $\mathrm{db} / \mathrm{db}$ mouse results in hyperphagia, severe obesity, hyperinsulinemia, and hyperglycemia beginning at $\sim 4$ weeks of age (Jackson Laboratories, http://jaxmice. jax.org/jaxmicedb/html/model_66.shtml). At 24 weeks of age (20 weeks of diabetes), $\mathrm{db} / \mathrm{db}$ mice exhibit insensitivity to mechanical and thermal stimuli, along with slowed nerve conduction velocities and reduced intra-epidermal nerve fiber (IENF) density (Sullivan et al. 2007, Cheng et al. 2009). Animals were maintained at the University of Michigan in a pathogen-free environment and cared for following the University of Michigan Committee on the Care and Use of Animals guidelines. Mice were given continuous access to food (Purina 5001, Purina Mills LLC, St Louis, MO, USA) and water.

Blood glucose (6-h fasting) and body weight were measured every 4 weeks to document the onset and duration of diabetes. One drop of tail blood was analyzed using a standard glucometer (One Touch Profile, LIFESCAN, Inc., Milpitas, CA, USA). At the end of the experimental period, glycated hemoglobin $(\mathrm{GHb})$ was measured using the Helena Laboratories Test Kit (Glyco-Tek Affinity Column Method).

\section{Tissue harvest}

Mice were killed by sodium pentobarbital overdose at 24 weeks of age, followed by transcardial PBS perfusion to remove residual contaminating blood. This method was chosen over $\mathrm{CO}_{2} /$ cervical dislocation (recommended by Stevens et al. (2000)) as $\mathrm{CO}_{2}$ /cervical dislocation is not compatible with transcardial perfusion, a step that was necessary to remove blood artifact and for collaborative use of the other tissues. The left sural and sciatic nerves and lumbar DRG were dissected, briefly rinsed in double-distilled water, frozen by immersion in liquid nitrogen, and stored at $-80^{\circ} \mathrm{C}$ until metabolomic analysis was conducted (eight $\mathrm{db} /+$ and $\mathrm{db} / \mathrm{db}$ DRG; nine $\mathrm{db} /+$ and $\mathrm{db} / \mathrm{db}$ sural nerve and sciatic nerve). The right sciatic nerve and lumbar DRG were dissected and immediately submerged in ice-cold antioxidant buffer, rapidly frozen by immersion in liquid nitrogen, and stored at $-80^{\circ} \mathrm{C}$ for quantification of end products of oxidative damage ( $\mathrm{six} \mathrm{db} /+$ and $\mathrm{db} / \mathrm{db} \mathrm{DRG} ; 12$ $\mathrm{db} /+\mathrm{and} \mathrm{db} / \mathrm{db}$ sciatic nerve). The right sciatic nerve from a separate cohort of mice was dissected, cut in thirds, and the proximal and distal thirds prepared as earlier for quantification of oxidative damage (six db/ + and six db/db). The left sciatic nerve and lumbar DRG were used for determination of aconitase enzyme activity as per manufacturer's instructions (Cayman Chemical Company, Ann Arbor, MI, USA). Although the method of killing confers a greater time from death to tissue harvest than $\mathrm{CO}_{2} /$ cervical dislocation, the timings were standardized across all mice (sural and sciatic nerves $8 \mathrm{~min}$, DRG $15 \mathrm{~min}$ ), allowing comparative results within this study.

\section{Targeted metabolomic analysis by LC/MS/MS}

Frozen tissue samples were extracted with $150 \mu$ l of chilled 8:1:1 methanol:chloroform:water containing ${ }^{13} \mathrm{C}$-labeled glycolysis and TCA cycle standards. Samples were sonicated on ice for $20 \mathrm{~s}$ ( $20 \%$ duty cycle, $20 \%$ maximum power), held at $4{ }^{\circ} \mathrm{C}$ for a further $5 \mathrm{~min}$, and centrifuged at $15000 \mathrm{~g}$ for $5 \mathrm{~min}$ at $4{ }^{\circ} \mathrm{C}$. Supernatant was transferred to autosampler vials and directly analyzed by LC/MS.

Chromatographic separation of 18 targeted glycolytic and TCA intermediates was performed based on the methods of Lorenz et al. (2011). Briefly, hydrophilic interaction liquid chromatography was performed using a Phenomenex Luna $\mathrm{NH}_{2}$ column $(3 \mu \mathrm{m}, 150 \times 1 \mathrm{~mm}$ i.d. $)$ on an Agilent 1200 RRLC coupled to an Agilent 6410 triple quadrupole mass spectrometer. Mobile phase A was $5 \mathrm{mM}$ ammonium acetate in water, adjusted to $\mathrm{pH} 9.9$ with ammonium hydroxide. Mobile phase B was acetonitrile. The initial gradient was a 10-min linear ramp from 20 to $100 \%$ B, followed by a 3 -min hold at $100 \%$ B. The mobile phase was returned to $20 \% \mathrm{~B}$ and held for $17 \mathrm{~min}$ for re-equilibration before the next run.

Published by Bioscientifica Ltd. 
The instrument was operated in multiple reaction monitoring (MRM) mode using MS/MS transitions previously optimized by analysis of authentic standards. The following parameters were implemented: flow rate was $0.07 \mathrm{ml} / \mathrm{min}$, column temperature $25^{\circ} \mathrm{C}$, injection volume $20 \mu \mathrm{l}$, spray voltage $4.0 \mathrm{kV}$ in negative ion mode, desolvation gas flow rate $10 \mathrm{l} / \mathrm{min}$, desolvation gas temperature $325^{\circ} \mathrm{C}$, and nebulizer pressure 40 psi.

The ratio of each metabolite peak area to that of the closest-matching ${ }^{13} \mathrm{C}$-labeled standard was calculated. Metabolite concentration was determined using calibration curves generated from known concentrations of authentic standards and equal concentrations of ${ }^{13} \mathrm{C}$-labeled compounds as were present in the samples. Concentrations were normalized to total protein content of the tissue sample, determined by the Bradford-Lowry method using the reagents and protocol supplied by BioRad Laboratories. Final values are expressed as picomole/ microgram tissue. Intermediates of the pathways not included in the LC/MS/MS output were due to lack of commercial availability of standard, insufficient concentration to reach detection limits, or degradation issues preventing accurate analysis by the current method.

\section{Oxidative stress measures}

DRG and sciatic nerve samples were analyzed for nitrated protein (3-nitrotyrosine) and oxidized lipids (hydroxyoctadecadienoic acids (HODEs)) as described previously (Wiggin et al. 2008, Vivekanandan-Giri et al. 2011). Tissue was homogenized at $4{ }^{\circ} \mathrm{C}$ in antioxidant buffer (100 $\mu \mathrm{M}$ diethylenetriaminepentaacetic acid, $50 \mu \mathrm{M}$ butylated hydroxytoluene, $1 \%(\mathrm{v} / \mathrm{v})$ ethanol, $10 \mathrm{mM} 3$-amino1,2,4-triazole, and $50 \mathrm{mM}$ sodium phosphate buffer (pH 7.4)) to prevent ex vivo oxidation, frozen, and thawed. Protein was precipitated with ice-cold trichloroacetic acid $(10 \% \mathrm{v} / \mathrm{v})$, collected by centrifugation, washed with $10 \%$ trichloroacetic acid, and delipidated twice with water/methanol/water-washed diethyl ether $(1: 3: 7 \mathrm{v} / \mathrm{v})$. Isotopically labeled internal standards were added and samples were hydrolyzed in $4 \mathrm{M}$ methane sulfonic acid at $110{ }^{\circ} \mathrm{C}$ for $24 \mathrm{~h}$ under argon as described previously (Pennathur et al. 2004). HODEs were quantified by reverse-phase C-18 HPLC analysis of triphenylphosphine-reduced lipid extracts after base hydrolysis. The protein content of tissue pellets was determined by a modified Lowry protein assay using BSA as a standard (Pennathur et al. 2005). Amino acids were isolated from the acid hydrolysate using a solid-phase C-18 column (Supelco; Pennathur et al. 2004, 2005) and quantified by MRM using isotope dilution LC/ESI/MS/MS as described previously (Vivekanandan-Giri et al. 2011). Results were normalized to tyrosine content, the precursor of 3-nitrotyrosine.

\section{Statistical analysis}

Data analysis was performed using GraphPad Prism 5.0 (GraphPad Software). Comparisons between groups were performed using either a one-way ANOVA with Tukey posttest for multiple comparisons or an unpaired $t$-test, as applicable. Assumptions about the Gaussian distribution of data and rules for transformation of nonnormative data were made as described previously (Russell et al. 1999). Significance was assigned when $P<0.05$.

\section{Results}

Metabolomic intermediates are decreased in sural nerve, sciatic nerve, and DRG tissue in $\mathrm{db} / \mathrm{db}$ mice

Diabetes was confirmed in $\mathrm{db} / \mathrm{db}$ mice by significant elevations in body weight, blood glucose, and $\mathrm{GHb}$ compared with their age-matched $\mathrm{db} /+$ controls $(P<0.001$; Table 1$)$. To begin to characterize the changes in glycolytic and TCA cycle intermediates within peripheral nervous system tissue of the $\mathrm{db} / \mathrm{db}$ mouse, we performed targeted LC/MS/MS metabolomic analysis on sural nerve, sciatic nerve, and DRG extracts (Table 2). At 24 weeks of age (20 weeks of diabetes), there was a significant decrease in four of the five measured glycolytic intermediates within both diabetic sural nerve and sciatic nerve compared with $\mathrm{db} /+$ controls (glucose-6phosphate/fructose-6-phosphate (G6P/F6P), 62, 45\%; 3-phosphoglycerate/2-phosphoglycerate (3PG/2PG), 75, 63\%; phosphoenolpyruvate (PEP), 75, 75\%; and lactate (LAC), 46, 56\% respectively), with additional diabetic decrease in fructose-1,6-bisphosphate (FBP) content of sural nerve (63\%; Table 2). By contrast, diabetes had no effect on measured glycolytic intermediates in DRG

Table 1 Body weight, fasting blood glucose, and GHb for $\mathrm{db} /+$ and $\mathrm{db} / \mathrm{db}$ mice at 24 weeks of age. Data are mean \pm s.E.M.

\begin{tabular}{|c|c|c|c|}
\hline Genotype & Weight (g) & $\begin{array}{l}\text { Blood glucose } \\
\text { (mg/dl) }\end{array}$ & GHb (\%) \\
\hline $\begin{array}{l}24 \text { weeks db/+ (9) } \\
24 \text { weeks db/db (9) }\end{array}$ & $\begin{array}{l}32.0 \pm 1.0 \\
52.6 \pm 4.8^{*}\end{array}$ & $\begin{array}{l}203 \pm 9 \\
672 \pm 67 *\end{array}$ & $\begin{array}{l}6.6 \pm 0.2 \\
13.7 \pm 0.4 \text { * }\end{array}$ \\
\hline
\end{tabular}

${ }^{*} P<0.001 \mathrm{vs} \mathrm{db} /+$. Nine $\mathrm{db} /+$ and $\mathrm{db} / \mathrm{db}$.

Published by Bioscientifica Ltd 
Table 2 Quantified LC/MS/MS metabolomic data from db/+ and db/db mouse sural nerve, sciatic nerve, and DRG. Data are mean picomole/microgram protein for each group \pm s.E.M.

\begin{tabular}{|c|c|c|c|c|c|c|}
\hline Metabolite & $\begin{array}{l}24 \text { weeks } \mathrm{db} /+ \\
\text { sural nerve }\end{array}$ & $\begin{array}{l}24 \text { weeks } \mathrm{db} / \mathrm{db} \\
\text { sural nerve }\end{array}$ & $\begin{array}{l}24 \text { weeks } \mathrm{db} /+ \\
\text { sciatic nerve }\end{array}$ & $\begin{array}{l}24 \text { weeks } \mathrm{db} / \mathrm{db} \\
\text { sciatic nerve }\end{array}$ & $\begin{array}{l}24 \text { weeks } \\
\text { db/+ DRG }\end{array}$ & $\begin{array}{l}24 \text { weeks } \\
\text { db/db DRG }\end{array}$ \\
\hline G6P/F6P & $16.3 \pm 4.9$ & $6.2 \pm 3.1 *$ & $10.9 \pm 1.9$ & $6.0 \pm 1.1^{*}$ & $5.5 \pm 1.0$ & $6.8 \pm 1.2$ \\
\hline FBP & $3.8 \pm 0.6$ & $1.4 \pm 0.3^{\dagger}$ & $9.7 \pm 1.6$ & $6.2 \pm 1.3$ & $7.1 \pm 0.9$ & $6.3 \pm 0.9$ \\
\hline $3 P G / 2 P G$ & $0.4 \pm 0.1$ & $0.1 \pm 0.03 *$ & $2.2 \pm 0.4$ & $0.8 \pm 0.2^{\dagger}$ & $0.1 \pm 0.03$ & $0.1 \pm 0.02$ \\
\hline PEP & $0.4 \pm 0.1$ & $0.1 \pm 0.02^{\dagger}$ & $0.4 \pm 0.1$ & $0.1 \pm 0.02^{\dagger}$ & $0.1 \pm 0.03$ & $0.1 \pm 0.03$ \\
\hline LAC & $136.8 \pm 19.0$ & $73.3 \pm 19.7 *$ & $220.7 \pm 45.8$ & $96.1 \pm 14.4^{*}$ & $149.8 \pm 14.7$ & $162.4 \pm 14.1$ \\
\hline CIT & $8.3 \pm 1.0$ & $4.3 \pm 0.6^{\dagger}$ & $49.7 \pm 6.9$ & $22.2 \pm 4.4^{\dagger}$ & $8.5 \pm 0.8$ & $5.6 \pm 0.4^{\dagger}$ \\
\hline ICIT & $0.2 \pm 0.03$ & $0.1 \pm 0.03 *$ & $0.6 \pm 0.1$ & $0.3 \pm 0.1$ * & $0.2 \pm 0.02$ & $0.1 \pm 0.01$ * \\
\hline SUC & $1.4 \pm 0.05$ & $1.1 \pm 0.2$ & $5.9 \pm 0.9$ & $4.7 \pm 0.8$ & $0.6 \pm 0.04$ & $0.9 \pm 0.2$ \\
\hline FUM & $4.4 \pm 0.4$ & $3.6 \pm 0.8$ & $6.0 \pm 1.1$ & $3.6 \pm 0.6$ & $4.9 \pm 0.6$ & $3.6 \pm 0.1$ \\
\hline MAL & $8.0 \pm 0.9$ & $6.2 \pm 1.0$ & $16.9 \pm 2.5$ & $11.5 \pm 2.0$ & $10.9 \pm 0.9$ & $10.6 \pm 0.7$ \\
\hline
\end{tabular}

$* P<0.05 ;{ }^{\dagger} P<0.01 \mathrm{vs} \mathrm{db} /+$. Eight $\mathrm{db} /+$ and db/db DRG; nine $\mathrm{db} /+$ and $\mathrm{db} / \mathrm{db}$ sciatic nerve and sural nerve; all data from male mice. G6P/F6P, glucose-6phosphate/fructose-6-phosphate; FBP, fructose-1,6-bisphosphate; $3 P G / 2 P G$, 3-phosphoglycerate/2-phosphoglycerate; PEP, phosphoenolpyruvate; LAC, lactate; CIT, citrate; ICIT, isocitrate; SUC, succinate; FUM, fumarate; MAL, malate.

(Table 2). Among the TCA cycle metabolites, citrate (CIT) and isocitrate (ICIT) were significantly lower in all three tissues from $\mathrm{db} / \mathrm{db}$ mice compared with $\mathrm{db} /+$ controls, with a greater decrease seen in sural nerve and sciatic nerve (48, 50\% sural nerve; 55, 50\% sciatic nerve; and 34, 50\% DRG). Sural nerve, sciatic nerve, and DRG content of the remaining measured TCA cycle intermediates were not significantly altered with diabetes (Table 2). These observations indicate that type 2 diabetes affects the TCA cycle metabolome of sural nerve, sciatic nerve, and DRG, as well as the glycolytic metabolome of the sural nerve and sciatic nerve, and suggest that the effect is greater in the peripheral nerve than the DRG.

\section{Protein oxidation and lipid peroxidation markers are elevated in sciatic nerve and DRG tissue in $\mathrm{db} / \mathrm{db}$ mice}

Oxidative stress is a major mechanism of hyperglycemiainduced DN in humans and rodents, particularly through the oxidation of proteins and lipids (Vincent \& Feldman 2004, Vincent et al. 2004, 2009b). Hydrogen peroxide $\left(\mathrm{H}_{2} \mathrm{O}_{2}\right)$ and $\mathrm{O}_{2}{ }^{-}$react with nitrite, derived from $\mathrm{NO}$, to produce peroxynitrite in peripheral nerves in experimental diabetes (Obrosova et al. 2005a). 3-Nitrotyrosine accumulates when peroxynitrite oxidizes tyrosine (Corbett et al. 1992, van der Veen \& Roberts 1999, Du et al. 2002). To confirm whether protein oxidation was elevated in the $\mathrm{db} / \mathrm{db}$ peripheral nervous system in vivo, we used isotope dilution LC/ESI/MS/MS to quantify levels of proteinbound 3-nitrotyrosine in sciatic nerve and DRG tissue from the $\mathrm{db} /+$ and $\mathrm{db} / \mathrm{db}$ mice (Fig. $1 \mathrm{~A}$ ). Nitrotyrosine in tissues of the peripheral nervous system was significantly increased by diabetes (sciatic nerve nitrotyrosine 2.3-fold increase, $P<0.001$; DRG nitrotyrosine 1.7-fold increase, $P<0.05)$. To determine whether lipid peroxidation was also elevated, we used HPLC to quantify HODEs in lipid extracts from the sciatic nerve and DRG of $\mathrm{db} /+$ and $\mathrm{db} / \mathrm{db}$ mice (Fig. 1A). The sciatic nerve and DRG samples from the $\mathrm{db} / \mathrm{db}$ mice contained significantly more HODEs than those from the $\mathrm{db} /+$ mice (sciatic nerve HODEs 2.4-fold increase, $P<0.001$; DRG HODEs 1.6-fold increase, $P<0.01)$. This increase in oxidized lipids was greater in sciatic nerve than in DRG $(P<0.05)$.

The data presented in Fig. 1A are those from whole sciatic nerve. Owing to the greater observed effect of diabetes on the metabolome of sural nerve and sciatic nerve than DRG (Table 2), and the peripheral presentation of signs of DN in rodents (Sullivan et al. 2007) and in humans (Edwards et al. 2008), we explored whether oxidative stress is greater distally in the sciatic nerve by repeating the analyses for 3-nitrotyrosine and HODEs on proximal and distal segments of the sciatic nerve from $\mathrm{db} /+$ and $\mathrm{db} / \mathrm{db}$ mice (Fig. $1 \mathrm{~B}$ and $\mathrm{C}$ ). There were no differences in oxidative stress measures between proximal and distal segments of $\mathrm{db} /+$ control nerves. Oxidized lipids (HODEs) were 2.3- and 2.6-fold greater in proximal and distal $\mathrm{db} / \mathrm{db}$ sciatic nerve respectively compared with those of $\mathrm{db} /+$ mice $(P<0.05)$. Furthermore, diabetic sciatic nerve HODEs were 1.6-fold greater distally than proximally $(P<0.05$; proximal $\mathrm{db} /+112 \pm 15$, proximal $\mathrm{db} / \mathrm{db} 252 \pm 35$, distal $\mathrm{db} /+152 \pm 16$, distal $\mathrm{db} / \mathrm{db}$ $391 \pm 56 \mathrm{pmol} / \mathrm{mg}$ protein; Fig. 1B). Nitrated protein was 2.3- and 2.2-fold greater in proximal and distal $\mathrm{db} / \mathrm{db}$ sciatic nerve respectively compared with those of $\mathrm{db} /+$ mice (proximal $\mathrm{db} /+216 \pm 54$, proximal $\mathrm{db} / \mathrm{db}$ $505 \pm 57 \mu \mathrm{mol} / \mathrm{mol}$ tyrosine, $P<0.01$; distal $\mathrm{db} /+335 \pm 45$,

Published by Bioscientifica Ltd. 
distal $\mathrm{db} / \mathrm{db} 739 \pm 142 \mu \mathrm{mol} / \mathrm{mol}$ tyrosine, $P<0.05)$. Nitrated protein content was not significantly altered proximally to distally in diabetic sciatic nerve (Fig. 1C).

Together, these observations indicate that type 2 diabetes increases both protein and lipid oxidation in $\mathrm{db} / \mathrm{db}$ mouse sciatic nerve and DRG. The diabetic increase in lipid peroxidation is greater in sciatic nerve than in DRG, and the extent of this oxidation is greater distally in sciatic nerve.
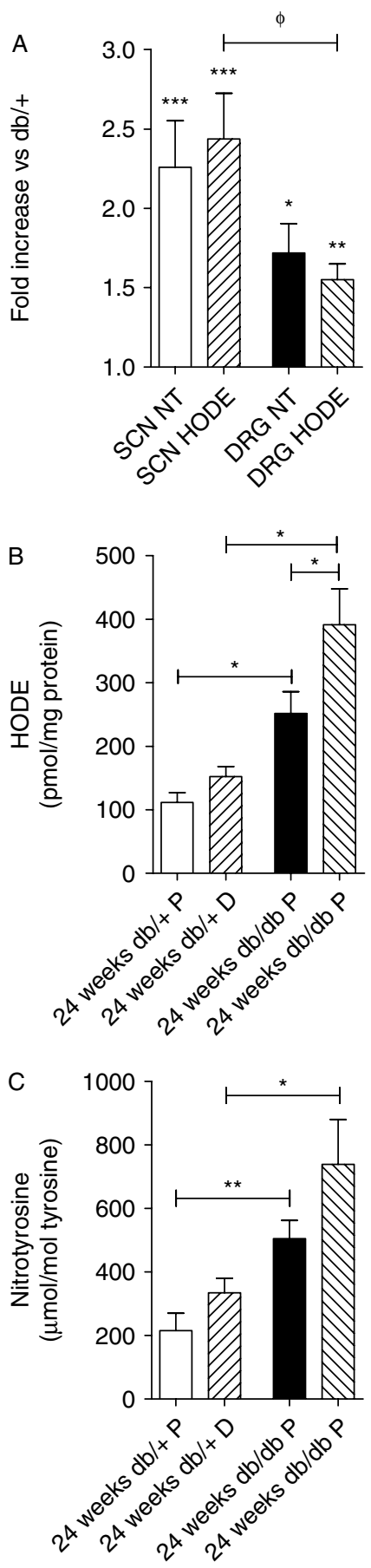

http://www.joe.endocrinology-journals.org DOI: $10.1530 / J O E-12-0356$

\section{Aconitase enzyme activity is decreased in sciatic nerve and DRG tissue in $\mathrm{db} / \mathrm{db}$ mice}

Aconitase catalyzes the conversion of CIT to ICIT in the TCA cycle and is the most sensitive TCA cycle enzyme to reactive oxygen species (ROS) inhibition (Tretter \& Adam-Vizi 2000). Work by Tretter \& Adam-Vizi (2000) established that when aconitase is inhibited, a segment of the TCA cycle between $\alpha$-ketoglutarate $(\alpha-K G)$ and oxaloacetate still functions via anaplerosis of glutamate in to the TCA cycle. To begin to understand the lack of change in TCA cycle intermediates other than CIT and ICIT, we measured aconitase enzyme activity in sciatic nerve and DRG from the $\mathrm{db} /+$ and $\mathrm{db} / \mathrm{db}$ mice (Fig. 2). Aconitase activity was 1.6-fold greater in DRG than sciatic nerve in control $(\mathrm{db} /+)$ mice (DRG $1.50 \pm 0.06$; sciatic nerve $0.96 \pm 0.10 \mu \mathrm{M} \mathrm{NADPH} / \mathrm{mg}$ protein per min, $P<0.01$ ), with this tissue difference maintained in the $\mathrm{db} / \mathrm{db}$ mice (DRG 0.91 \pm 0.12 ; sciatic nerve $0.46 \pm 0.06 \mu \mathrm{M}$ $\mathrm{NADPH} / \mathrm{mg}$ protein per min $P<0.05)$. Type 2 diabetes was associated with a decrease in aconitase activity, with a greater effect in sciatic nerve than DRG (DRG 0.39 -fold decrease, $P<0.01$; sciatic nerve 0.51 -fold decrease, $P<0.01)$.

\section{Discussion}

Recent metabolomic studies in models of type 1 diabetes reported downregulation of key TCA cycle and mitochondrial proteins (Akude et al. 2011) and enzyme activities (Chowdhury et al. 2010) in DRG and upregulation of TCA cycle and mitochondrial proteins in Schwann

\section{Figure 1}

Increased oxidative stress in diabetic sciatic nerve and DRG. (A) Fold changes in oxidative stress measures from whole sciatic nerve and DRG were calculated from the ratio of $\mathrm{db} / \mathrm{db}$ to $\mathrm{db} /+$. The nitrated protein content and HODEs were increased in whole sciatic nerve and DRG from diabetic mice compared with those from $\mathrm{db} /+$ controls $(* P<0.05$; $* * P<0.01$; and $* * * P<0.001 \mathrm{vs} \mathrm{db} /+)$. The diabetic fold increase in oxidized lipids was greater in sciatic nerve than in DRG $\left({ }^{\phi} P<0.05\right)$. Data expressed as mean fold-change \pm s.E.M.; six db/ + and db/db DRG; $12 \mathrm{db} /+$ and db/db sciatic nerve. There were no changes in oxidative stress measures between proximal and distal segments of $\mathrm{db} /+$ control sciatic nerves ( $B$ and $C$ ). (B) Oxidized lipids (HODEs) were elevated in proximal and distal $\mathrm{db} / \mathrm{db}$ sciatic nerve respectively compared with those of $\mathrm{db} /+$ mice. Diabetic sciatic nerve HODEs were greater distally than proximally. (C) The nitrotyrosine-to-tyrosine ratio was elevated in proximal and distal $\mathrm{db} / \mathrm{db}$ sciatic nerve respectively compared with those of $\mathrm{db} /+$ mice. Data expressed as mean \pm s.E.M.; six $\mathrm{db} /+$ and $\mathrm{db} / \mathrm{db}$ sciatic nerve. ${ }^{*} P<0.05$ and $* * P<0.01$. SCN, sciatic nerve; DRG, dorsal root ganglia; $P$, proximal; $D$, distal; NT, 3-nitrotyrosine. All data from male mice.

Published by Bioscientifica Ltd. 


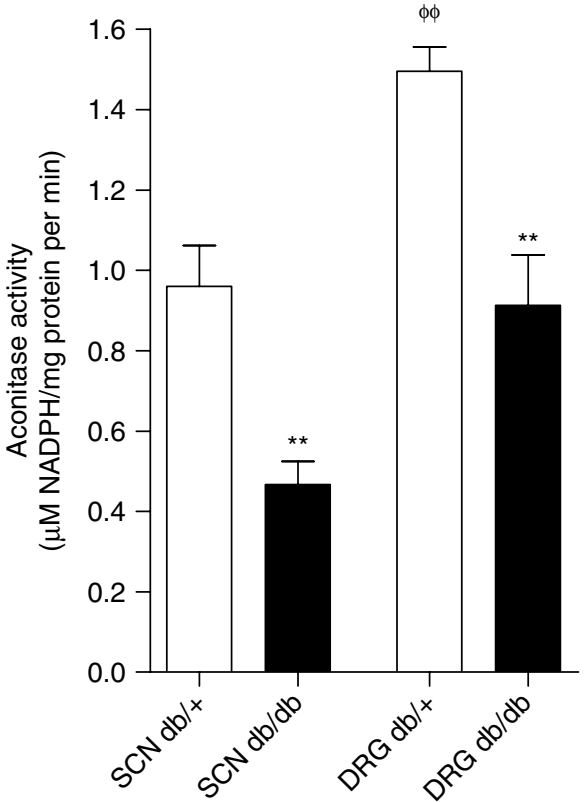

\section{Figure 2}

Decrease in aconitase enzyme activity in diabetic sciatic nerve and DRG aconitase activity was 1.6 -fold greater in DRG than in sciatic nerve in control $(\mathrm{db} /+)$ mice $\left({ }^{\phi \phi} P<0.01\right)$, with this tissue difference maintained in the $\mathrm{db} / \mathrm{db}$ mice. Type 2 diabetes was associated with a decrease in aconitase activity in both tissues ( $* * P<0.01$ compared with $\mathrm{db} /+$ ). Data expressed as mean \pm s.E.M.; six db/+ and db/db. SCN, sciatic nerve; DRG, dorsal root ganglia. All data from male mice.

cells (Zhang et al. 2010). Differences in metabolic profiles, prevalence of DN, and efficacy of glycemic control on DN in type 1 diabetes and type 2 diabetes suggest that therapeutic strategies based on models of type 1 diabetes may offer limited efficacy to the type 2 diabetic patient with DN (Callaghan et al. 2012). There is therefore a critical need to understand peripheral nerve-specific metabolomic changes in type 2 diabetes, and their role in nerve injury, to develop disease-modifying treatments. To this end, we evaluated changes in the glycolytic and TCA cycle metabolomes of key components of the peripheral nervous system in the $\mathrm{db} / \mathrm{db}$ mouse model of type 2 diabetes. We performed targeted LC/MS/MS metabolomic analysis on sural nerve, sciatic nerve, and DRG from $\mathrm{db} / \mathrm{db}$ mice. To confirm that ROS is elevated in the $\mathrm{db} / \mathrm{db}$ peripheral nervous system, we used both LC/ESI/MS/MS and HPLC to measure nitrated protein and peroxidated lipid content respectively. We observed decreased glycolytic and TCA cycle intermediates in the $\mathrm{db} / \mathrm{db}$ tissue, with concurrent increases in protein and lipid oxidation. Additionally, our data suggest a greater metabolic impact of diabetes distally, a proximal-distal increase in the severity of oxidative stress, and a proximal-distal decrease in aconitase enzyme activity in the $\mathrm{db} / \mathrm{db}$ nerve.

Oxidative stress is strongly implicated in DN pathogenesis, particularly through the oxidation of proteins and lipids (Vincent \& Feldman 2004, Vincent et al. 2004, $2009 b$ ). To confirm whether protein and lipid oxidation are elevated in the $\mathrm{db} / \mathrm{db}$ peripheral nervous system in vivo, we quantified levels of protein-bound 3-nitrotyrosine in tissue extracts, and HODEs in lipid extracts respectively from the sciatic nerve and DRG of $\mathrm{db} /+$ and $\mathrm{db} / \mathrm{db}$ mice. Nitrotyrosine and HODEs were significantly elevated in the $\mathrm{db} / \mathrm{db}$ peripheral nerve and DRG (Fig. 1), consistent with previous work showing that diabetes increases neuronal oxidized protein (Vincent et al. 2004, 2005, Obrosova et al. 2005a, Pennathur et al. 2005, Wiggin et al. 2008) and lipids (Vincent et al. 2004, 2005, Wiggin et al. 2008). Elevated oxidized proteins and oxidized lipids in distal diabetic sciatic nerve compared with distal control sciatic nerve indicate greater oxidative stress at peripheral nerve extremities in diabetes (Fig. 1B and C), paralleling the dyingback axonopathy observed in animal models (Sullivan et al. 2007) and human patients (Edwards et al. 2008). The diabetic elevation in lipid peroxidation (HODEs) was greater in the sciatic nerve than in the DRG and increased moving distally along the $\mathrm{db} / \mathrm{db}$ sciatic nerve (Fig. 1). There are at least two possible explanations for these findings. First, the increased HODEs as a measure of oxidative stress could simply represent the greater lipid content in sciatic nerve compared with DRG (data not shown) or, alternatively, the increase is a true reflection of impaired axonal function with secondary impairment of axon/Schwann cell interactions leading to Schwann cell injury. To our knowledge, these are novel data that oxidative stress increases proximally-to-distally in the neuropathic diabetic peripheral nerve. $\mathrm{DN}$ predominantly occurs in a distal symmetrical pattern, with skin denervation (reduced IENF density; Said 2007, Sullivan et al. 2007) increasing with diabetes duration (Shun et al. 2004), and proximal-to-distal graded loss of myelinated fiber density observed in diabetic patients (Sullivan et al. 2003). The current data suggest that there may be a link between this proximal-to-distal graded loss of myelinated fiber density and a graded increase in oxidative stress. In addition to its role in nitration of proteins (Corbett et al. 1992, van der Veen \& Roberts 1999, Du et al. 2002, Obrosova et al. 2005a), peroxynitrite formation is required for myelin-lipid peroxidation in in vitro myelin suspensions (van der Veen \& Roberts 1999); the greater fold increases observed in sciatic nerve than in DRG lipid peroxidation measures (Fig. 1A) may reflect oxidation of myelin in the peripheral nerve.

Published by Bioscientifica Ltd. 
Aconitase catalyzes the conversion of CIT to ICIT in the TCA cycle and is the most sensitive TCA cycle enzyme to ROS inhibition (Tretter \& Adam-Vizi 2000). To begin to understand the specificity of the change in CIT and ICIT TCA cycle intermediates, we measured aconitase enzyme activity in sciatic nerve and DRG from the $\mathrm{db} /+$ and $\mathrm{db} / \mathrm{db}$ mice. The diabetes-related depletion of aconitase activity (Fig. 2) is consistent with our previous report in cultured DRG neurons (Vincent et al. 2005). The greater diabetic impairment observed in sciatic nerve than DRG is likely related to greater oxidative stress-mediated aconitase inhibition (Gardner \& Fridovich 1992, Gardner et al. 1995, Tretter \& Adam-Vizi 2000) in the sciatic nerve. This is contradictory to our previous in vitro observation that DRG neurons are more susceptible to oxidative stress than non-myelinating Schwann cells (Vincent et al. 2009c). It is important to note that our 2009 study investigated the effects of mild, acute oxidative stress induced by high glucose and $\mathrm{H}_{2} \mathrm{O}_{2}$ in cells derived from immature rat embryos and pups. We did not assess the effects of myelinlipid peroxidation, or high free fatty acids and elevated ox-LDL, both of which are associated with type 2 diabetes and linked to oxidative stress-mediated injury in these cells (Vincent et al. 2009a, Suzuki et al. 2011).

LAC production via the reversible LAC dehydrogenase-catalyzed reaction from pyruvate, the last metabolic intermediate of glycolysis, is intimately linked to the $\mathrm{NAD}+/ \mathrm{NADH}$ cellular redox status. Further flux experiments are required, but the pattern of glycolytic and TCA cycle intermediates in the sural nerve and sciatic nerve in diabetic mice compared with controls suggests that the observed significant depletion of sural nerve and sciatic nerve LAC (Table 2) is related to inhibition of glycolysis. These data are in contrast with findings of elevated LAC in sciatic nerve from type 1 diabetic streptozotocin (STZ)treated rats (Obrosova et al. 1999, Stevens et al. 2000). Our finding that LAC levels were unchanged in $\mathrm{db} / \mathrm{db}$ DRG is in agreement with reports in STZ-diabetic lens (Obrosova et al. 1998, Obrosova \& Stevens 1999). Work by Stevens et al. (2000) highlighted concerns over anesthetic-induced elevations in LAC levels in control peripheral nerves when compared with the $\mathrm{CO}_{2}$ /cervical dislocation method of killing. Absolute values stated in Table 2 may therefore be an underestimate of true tissue LAC content, but relative comparisons between $\mathrm{db} /+$ and $\mathrm{db} / \mathrm{db}$ mice may be made. Interestingly, the observed depletions in $\mathrm{db} / \mathrm{db}$ sural and sciatic nerves are in contrast with elevations reported in STZ rats killed via the $\mathrm{CO}_{2} /$ cervical dislocation method (Obrosova et al. 1999, Stevens et al. 2000). The significant decrease in LAC content we observe argues against the potential for an anesthesia-driven LAC elevation to introduce artifact into the data. In addition, it should be noted that the above studies by Obrosova and Stevens were performed in a model of type 1 diabetes in rats and over shorter diabetes duration (3-6 weeks).

Our finding that G6P and F6P were decreased in sciatic nerve, with additional decrease in FBP in sural nerve, in $\mathrm{db} / \mathrm{db}$ mice at 24 weeks of age (Table 2), is in contrast to findings in STZ diabetic lens (Obrosova et al. 1998, Obrosova \& Stevens 1999). As G6P and F6P are derived from the same pool in the current MS approach, we cannot determine the contribution from each intermediate to the observed measurements. Whether there is a true decrease in both F6P and upstream G6P or a decrease in F6P due to redirection of G6P into the polyol (or other) pathways remains unclear.

Hexokinase saturation and maximal glycolytic flux is one proposed mechanism underlying the accumulation of nerve glucose and its direction into the polyol pathway in diabetes (Tomlinson \& Gardiner 2008). Gardiner et al. (2007) observed diminished hexokinase activity in DRG from STZ diabetic rats. Studies on excised rat retinas (Ola et al. 2006) concluded that glycolysis and glucose metabolism downstream of hexokinase are not elevated by hyperglycemia or type 1 diabetes but that intermediates of alternative glucose metabolism, such as those of the polyol pathway, are increased. This is in agreement with conclusions of studies by the Greene group in STZ diabetic rat sciatic nerve (Obrosova et al. 1999, Stevens et al. 2000). Thus, it is possible that glucose is being preferentially directed into the polyol pathway in the $\mathrm{db} / \mathrm{db}$ sural nerve and sciatic nerve, away from energy-producing glycolysis.

Decreased steady-state concentrations of metabolites in the lower segment of glycolysis (3PG/2PG; PEP) in $\mathrm{db} / \mathrm{db}$ sural and sciatic nerves compared with controls agrees with previously published reports in the STZ diabetic lens (Obrosova et al. 1998, Obrosova \& Stevens 1999; levels of these intermediates were similar between control and diabetic DRG in the current study), which concluded that sites of regulation are at glyceraldehyde 3-phosphate dehydrogenase (GAPDH) reaction and downstream (e.g. enolase and pyruvate kinase). This conclusion is supported in the current model by our recent report of downregulation of the gene encoding enolase (Eno2) in $\mathrm{db} / \mathrm{db}$ sciatic nerve at 24 weeks of age (Pande et al. 2011), the fact that GAPDH is vulnerable to oxidative damage (Du et al. 2000 ), and greater markers of lipid and protein oxidative damage in distal sciatic nerve compared with DRG (Fig. 1). In the more distal sural nerve, data suggest additional upstream sites of glycolysis inhibition (e.g. hexokinase,

Published by Bioscientifica Ltd. 
phosphoglucose isomerase, and phosphofructokinase), with a greater diabetic decrease in metabolic intermediates in sural nerve compared with sciatic nerve (Table 2). In addition, slow axonal transport, responsible for the transport of glycolytic enzymes, is impaired in $\mathrm{db} / \mathrm{db}$ diabetes at 20-24 weeks of age (Vitadello et al. 1983, 1985). Decreased peripheral enzyme availability coupled with increased distal oxidative stress may be related to the greater distal metabolomic changes observed in the current study.

Our observed decreases in CIT and ICIT (Table 2) are consistent with work by Akude et al. reporting downregulation of key TCA cycle proteins, including CIT synthase, in DRG from 22-week STZ diabetic rats (Akude et al. 2011). One question arising from the TCA cycle metabolomic data is the lack of change in additional intermediates other than CIT and ICIT. Aconitase, catalyzing the CIT to ICIT reaction in the TCA cycle (Fig. 3), is inhibited by ROS, including $\mathrm{O}_{2}{ }^{-}$(Gardner \& Fridovich 1992, Gardner et al. 1995) and $\mathrm{H}_{2} \mathrm{O}_{2}$ (Tretter \& Adam-Vizi 2005). When aconitase is fully inhibited by $\mathrm{H}_{2} \mathrm{O}_{2}$ in nerve terminals, $\alpha$-KG dehydrogenase ( $\alpha$-KGDH;

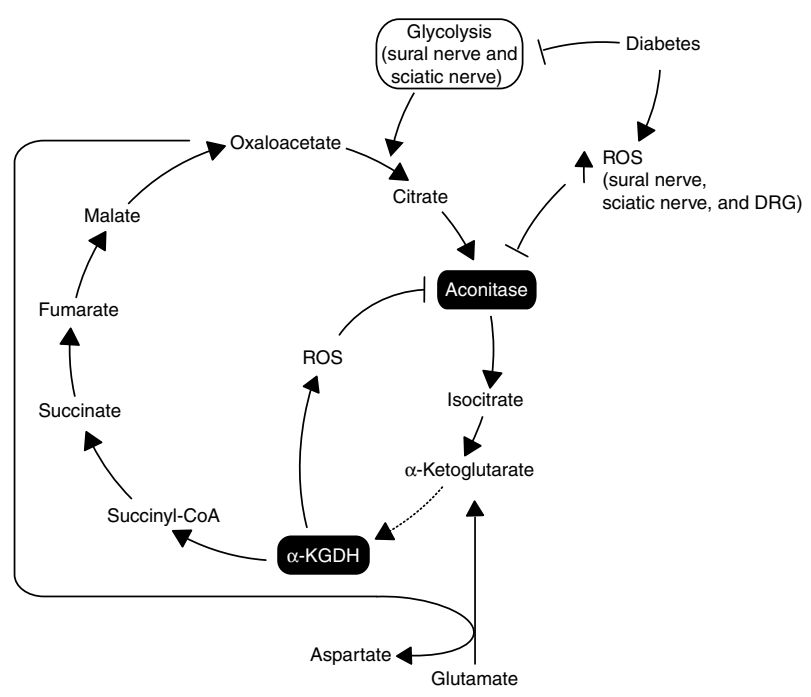

Figure 3

Proposed relationship between diabetes, ROS, and the TCA cycle. ROSmediated inhibition of aconitase may truncate the TCA cycle in diabetic sural nerve, sciatic nerve, and DRG (bold arrows). This would result in the observed maintenance of succinate, fumarate, and malate levels in the face of decreased citrate and isocitrate. Reduced glycolytic intermediates feeding into the TCA cycle in sural and sciatic nerves may contribute to the observed decreases in citrate and isocitrate and be interpreted as a glucosedeficient state. Activation of the $\alpha$-KG-utilizing truncated TCA cycle pathway in the sural and sciatic nerves would further contribute to ROS production and to the greater oxidative stress observed in diabetic sciatic nerve than DRG. $\alpha-K G D H, \alpha$-ketoglutarate dehydrogenase; DRG, dorsal root ganglia; TCA, tricarboxylic acid; ROS, reactive oxygen species. catalyzing the $\alpha-\mathrm{KG}$ to succinyl-CoA reaction) remains functional and a segment of the TCA cycle $(\alpha-K G$ to oxaloacetate) is maintained by glutamate, which is converted to $\alpha$-KG via transamination (see Tretter \& Adam-Vizi (2005)) for comprehensive explanation). ROS-mediated inhibition of aconitase (Fig. 2) may activate this truncated TCA in diabetic sural nerve, sciatic nerve, and DRG (Fig. 3), explaining the maintenance of levels of succinate, fumarate, and malate in the face of decreased CIT and ICIT observed in this study. This truncated segment of the TCA cycle may function in the absence of glucose (Yudkoff et al. 1994, Erecinska et al. 1996). In this respect, a state of oxidative stress when aconitase is completely inhibited but $\alpha$-KGDH remains active is similar to a glucose-free state. Additionally, $\alpha$-KGDH is itself a source of ROS production (see Gibson et al. (2010) for review of $\alpha-\mathrm{KGDH}$ in neurodegeneration), the level of which increases when $\alpha$-KG is utilized as a fuel source over glucose in isolated brain synaptosomes (Tretter \& Adam-Vizi 2004). The greater decrease in CIT and ICIT observed in $\mathrm{db} / \mathrm{db}$ sural and sciatic nerves (compared with DRG) may be due to reduced anaplerosis of intermediates from upstream glycolysis to the TCA cycle. This may be interpreted as a glucose-deficient state, activating the $\alpha$-KG-utilizing truncated TCA cycle pathway, further contributing to ROS production, and potentially contributing to the greater degree of oxidative stress observed in diabetic sciatic nerve than in DRG (Fig. 1A). Contribution to these pathways from an altered diabetic lipid metabolome should be considered but has not been explored in the current study.

Collectively, our data and those of the Fernyhough, LaNoue, and Obrosova groups support the emerging idea of tissue-specific alterations in energy metabolism in diabetic complications-prone tissues such as the peripheral nerve (Gardiner et al. 2007, Chowdhury et al. 2010, Akude et al. 2011), retina (Ola et al. 2006), and lens (Obrosova et al. 1998, Obrosova \& Stevens 1999). For the first time, we expand this knowledge to neuropathy in a type 2 model of diabetes, additionally demonstrating different metabolomic profiles within specific tissues of the peripheral nervous system. The greater metabolomic changes in sural nerve and sciatic nerve than DRG may reflect increased oxidative stress and subsequent inhibition of key metabolic enzymes, including aconitase. However, our static measurements of metabolites are not direct indicators of flux through a pathway: these data are the beginnings of a full characterization of bioenergetic alterations in diabetic peripheral nerve and are necessary to develop effective disease-modifying treatments for $\mathrm{DN}$.

Published by Bioscientifica Ltd. 


\section{Declaration of interest}

The authors declare that there is no conflict of interest that could be perceived as prejudicing the impartiality of the research reported.

\section{Funding}

This work was supported by the National Institutes of Health (NIH 1 DP3 DK094292, NIH 1 R24 DK082841-01, NIH 1 UO1 DK076160, and NIH 1RC 1NS068182 (to E L F)), The A. Alfred Taubman Medical Research Institute and The Program for Neurology Research and Discovery. This work utilized Molecular Phenotyping Core Services of the Michigan Nutrition and Obesity Research Center, supported by the National Institutes of Health (DK089503; University of Michigan).

\section{Acknowledgements}

The authors thank Drs Anne M Heacock, Stacey A Sakowski, and Kelli A Sullivan for critical review of the manuscript, and Mrs Judith Bentley for assistance with preparation of the manuscript.

\section{References}

Akude E, Zherebitskaya E, Chowdhury SK, Smith DR, Dobrowsky RT \& Fernyhough P 2011 Diminished superoxide generation is associated with respiratory chain dysfunction and changes in the mitochondrial proteome of sensory neurons from diabetic rats. Diabetes 60 288-297. (doi:10.2337/db10-0818)

Brownlee M 2001 Biochemistry and molecular cell biology of diabetic complications. Nature 414 813-820. (doi:10.1038/414813a)

Callaghan BC, Hur J \& Feldman EL 2012 Diabetic neuropathy: one disease or two? Current Opinion in Neurology 25 536-541. (doi:10.1097/ WCO.0b013e328357a797)

CDCP 2011 National diabetes fact sheet: national estimates and general information on diabetes and prediabetes in the United States. U.S. Department of Health and Human Services, Centers for Disease Control and Prevention, Atlanta, GA.

Cheng HT, Dauch JR, Hayes JM, Hong Y \& Feldman EL 2009 Nerve growth factor mediates mechanical allodynia in a mouse model of type 2 diabetes. Journal of Neuropathology and Experimental Neurology 68 1229-1243. (doi:10.1097/NEN.0b013e3181bef710)

Chowdhury SK, Zherebitskaya E, Smith DR, Akude E, Chattopadhyay S, Jolivalt CG, Calcutt NA \& Fernyhough P 2010 Mitochondrial respiratory chain dysfunction in dorsal root ganglia of streptozotocininduced diabetic rats and its correction by insulin treatment. Diabetes 59 1082-1091. (doi:10.2337/db09-1299)

Corbett JA, Tilton RG, Chang K, Hasan KS, Ido Y, Wang JL, Sweetland MA, Lancaster JR Jr, Williamson JR \& McDaniel ML 1992 Aminoguanidine, a novel inhibitor of nitric oxide formation, prevents diabetic vascular dysfunction. Diabetes 41 552-556. (doi:10.2337/diabetes.41.4.552)

Du XL, Edelstein D, Rossetti L, Fantus IG, Goldberg H, Ziyadeh F, Wu J \& Brownlee M 2000 Hyperglycemia-induced mitochondrial superoxide overproduction activates the hexosamine pathway and induces plasminogen activator inhibitor-1 expression by increasing Sp1 glycosylation. PNAS 97 12222-12226. (doi:10.1073/pnas.97.22. 12222)

Du Y, Smith MA, Miller CM \& Kern TS 2002 Diabetes-induced nitrative stress in the retina, and correction by aminoguanidine. Journal of Neurochemistry 80 771-779. (doi:10.1046/j.0022-3042.2001.00737.x)

Edwards JL, Vincent AM, Cheng HT \& Feldman EL 2008 Diabetic neuropathy: mechanisms to management. Pharmacology \& Therapeutics 120 1-34. (doi:10.1016/j.pharmthera.2008.05.005)
Erecinska M, Nelson D, Deas J \& Silver IA 1996 Limitation of glycolysis by hexokinase in rat brain synaptosomes during intense ion pumping. Brain Research 726 153-159. (doi:10.1016/0006-8993(96)00324-1)

Feldman EL 2008 Diabetic neuropathy. Current Drug Targets 9 1-2. (doi:10.2174/138945008783431709)

Gardiner NJ, Wang Z, Luke C, Gott A, Price SA \& Fernyhough P 2007 Expression of hexokinase isoforms in the dorsal root ganglion of the adult rat and effect of experimental diabetes. Brain Research 1175 143-154. (doi:10.1016/j.brainres.2007.08.015)

Gardner PR \& Fridovich I 1992 Inactivation-reactivation of aconitase in Escherichia coli. A sensitive measure of superoxide radical. Journal of Biological Chemistry 267 8757-8763.

Gardner PR, Raineri I, Epstein LB \& White CW 1995 Superoxide radical and iron modulate aconitase activity in mammalian cells. Journal of Biological Chemistry 270 13399-13405. (doi:10.1074/jbc.270.16.9137)

Gibson GE, Starkov A, Blass JP, Ratan RR \& Beal MF 2010 Cause and consequence: mitochondrial dysfunction initiates and propagates neuronal dysfunction, neuronal death and behavioral abnormalities in age-associated neurodegenerative diseases. Biochimica et Biophysica Acta 1802 122-134. (doi:10.1016/j.bbadis.2009.08.010)

Greene DA \& Winegrad AI 1979 In vitro studies of the substrates for energy production and the effects of insulin on glucose utilization in the neural components of peripheral nerve. Diabetes 28 878-887. (doi:10.2337/diabetes.28.10.878)

Kishi Y, Schmelzer JD, Yao JK, Zollman PJ, Nickander KK, Tritschler HJ \& Low PA $1999 \alpha$-Lipoic acid: effect on glucose uptake, sorbitol pathway, and energy metabolism in experimental diabetic neuropathy. Diabetes 48 2045-2051. (doi:10.2337/diabetes.48.10.2045)

Lorenz MA, Burant CF \& Kennedy RT 2011 Reducing time and increasing sensitivity in sample preparation for adherent mammalian cell metabolomics. Analytical Chemistry 83 3406-3414. (doi:10.1021/ac103313x)

Obrosova IG \& Stevens MJ 1999 Effect of dietary taurine supplementation on GSH and NAD(P)-redox status, lipid peroxidation, and energy metabolism in diabetic precataractous lens. Investigative Ophthalmology \& Visual Science 40 680-688. (doi:10.1007/s001250051290)

Obrosova I, Cao X, Greene DA \& Stevens MJ 1998 Diabetes-induced changes in lens antioxidant status, glucose utilization and energy metabolism: effect of DL- $\alpha$-lipoic acid. Diabetologia 41 1442-1450. (doi:10.1007/s001250051090)

Obrosova IG, Fathallah L, Lang HJ \& Greene DA 1999 Evaluation of a sorbitol dehydrogenase inhibitor on diabetic peripheral nerve metabolism: a prevention study. Diabetologia 42 1187-1194. (doi:10.1007/ s001250051290)

Obrosova IG, Mabley JG, Zsengeller Z, Charniauskaya T, Abatan OI, Groves JT \& Szabo C 2005a Role for nitrosative stress in diabetic neuropathy: evidence from studies with a peroxynitrite decomposition catalyst. FASEB Journal 19 401-403. (doi:10.1096/fj.04-1913fje)

Obrosova IG, Pacher P, Szabo C, Zsengeller Z, Hirooka H, Stevens MJ \& Yorek MA $2005 b$ Aldose reductase inhibition counteracts oxidativenitrosative stress and poly(ADP-ribose) polymerase activation in tissue sites for diabetes complications. Diabetes 54 234-242. (doi:10.2337/ diabetes.54.1.234)

Ola MS, Berkich DA, Xu Y, King MT, Gardner TW, Simpson I \& LaNoue KF 2006 Analysis of glucose metabolism in diabetic rat retinas. American Journal of Physiology. Endocrinology and Metabolism 290 E1057-E1067. (doi:10.1152/ajpendo.00323.2005)

Pande M, Hur J, Hong Y, Backus C, Hayes JM, Oh SS, Kretzler M \& Feldman EL 2011 Transcriptional profiling of diabetic neuropathy in the BKS db/db mouse: a model of type 2 diabetes. Diabetes 60 1981-1989. (doi:10.2337/db10-1541)

Pennathur S, Bergt C, Shao B, Byun J, Kassim SY, Singh P, Green PS, McDonald TO, Brunzell J, Chait A et al. 2004 Human atherosclerotic intima and blood of patients with established coronary artery disease contain high density lipoprotein damaged by reactive nitrogen species. Journal of Biological Chemistry 279 42977-42983. (doi:10.1074/jbc. M406762200) 
Pennathur S, Ido Y, Heller JI, Byun J, Danda R, Pergola P, Williamson JR \& Heinecke JW 2005 Reactive carbonyls and polyunsaturated fatty acids produce a hydroxyl radical-like species: a potential pathway for oxidative damage of retinal proteins in diabetes. Journal of Biological Chemistry 280 22706-22714. (doi:10.1074/jbc.M500839200)

Russell JW, Sullivan KA, Windebank AJ, Herrmann DN \& Feldman EL 1999 Neurons undergo apoptosis in animal and cell culture models of diabetes. Neurobiology of Disease 6 347-363. (doi:10.1006/nbdi. 1999.0254)

Said G 2007 Diabetic neuropathy - a review. Nature Clinical Practice. Neurology 3 331-340. (doi:10.1038/ncpneuro0504)

Shun CT, Chang YC, Wu HP, Hsieh SC, Lin WM, Lin YH, Tai TY \& Hsieh ST 2004 Skin denervation in type 2 diabetes: correlations with diabetic duration and functional impairments. Brain 127 1593-1605. (doi:10.1093/brain/awh180)

Stevens MJ, Obrosova I, Cao X, Van Huysen C \& Greene DA 2000 Effects of DL- $\alpha$-lipoic acid on peripheral nerve conduction, blood flow, energy metabolism, and oxidative stress in experimental diabetic neuropathy. Diabetes 49 1006-1015. (doi:10.2337/diabetes.49.6.1006)

Sullivan KA, Brown MS, Harmon L \& Greene DA 2003 Digital electron microscopic examination of human sural nerve biopsies. Journal of the Peripheral Nervous System 8 260-270. (doi:10.1111/j.1085-9489.2003. 03030.x)

Sullivan KA, Hayes JM, Wiggin TD, Backus C, Su Oh S, Lentz SI, Brosius F III \& Feldman EL 2007 Mouse models of diabetic neuropathy. Neurobiology of Disease 28 276-285. (doi:10.1016/j.nbd. 2007.07.022)

Suzuki J, Akahane K, Nakamura J, Naruse K, Kamiya H, Himeno T, Nakamura N, Shibata T, Kondo M, Nagasaki H et al. 2011 Palmitate induces apoptosis in Schwann cells via both ceramide-dependent and independent pathways. Neuroscience 176 188-198. (doi:10.1016/ j.neuroscience.2010.11.035)

Thurston JH, McDougal DB Jr, Hauhart RE \& Schulz DW 1995 Effects of acute, subacute, and chronic diabetes on carbohydrate and energy metabolism in rat sciatic nerve. Relation to mechanisms of peripheral neuropathy. Diabetes 44 190-195. (doi:10.2337/diabetes.44.2.190)

Tomlinson DR \& Gardiner NJ 2008 Glucose neurotoxicity. Nature Reviews. Neuroscience 9 36-45. (doi:10.1038/nrn2294)

Tretter L \& Adam-Vizi V 2000 Inhibition of Krebs cycle enzymes by hydrogen peroxide: a key role of $[\alpha]$-ketoglutarate dehydrogenase in limiting NADH production under oxidative stress. Journal of Neuroscience 20 8972-8979.

Tretter L \& Adam-Vizi V 2004 Generation of reactive oxygen species in the reaction catalyzed by $\alpha$-ketoglutarate dehydrogenase. Journal of Neuroscience 24 7771-7778. (doi:10.1523/JNEUROSCI.1842-04.2004)

Tretter L \& Adam-Vizi V $2005 \alpha$-Ketoglutarate dehydrogenase: a target and generator of oxidative stress. Philosophical Transactions of the Royal Society of London. Series B, Biological Sciences $3602335-2345$. (doi:10.1098/rstb.2005.1764)

van der Veen RC \& Roberts LJ 1999 Contrasting roles for nitric oxide and peroxynitrite in the peroxidation of myelin lipids. Journal of Neuroimmunology 95 1-7. (doi:10.1016/S0165-5728(98)00239-2)
Vincent AM \& Feldman EL 2004 New insights into the mechanisms of diabetic neuropathy. Reviews in Endocrine \& Metabolic Disorders 5 227-236. (doi:10.1023/B:REMD.0000032411.11422.e0)

Vincent AM, Russell JW, Low P \& Feldman EL 2004 Oxidative stress in the pathogenesis of diabetic neuropathy. Endocrine Reviews 25 612-628. (doi:10.1210/er.2003-0019)

Vincent AM, McLean LL, Backus C \& Feldman EL 2005 Short-term hyperglycemia produces oxidative damage and apoptosis in neurons. FASEB Journal 19 638-640. (doi:10.1096/fj.04-2513fje)

Vincent AM, Hayes JM, McLean LL, Vivekanandan-Giri A, Pennathur S \& Feldman EL 2009a Dyslipidemia-induced neuropathy in mice: the role of oxLDL/LOX-1. Diabetes $\mathbf{5 8}$ 2376-2385. (doi:10.2337/ db09-0047)

Vincent AM, Hinder LM, Pop-Busui R \& Feldman EL 2009b Hyperlipidemia: a new therapeutic target for diabetic neuropathy. Journal of the Peripheral Nervous System 14 257-267. (doi:10.1111/j.1529-8027.2009. 00237.x)

Vincent AM, Kato K, McLean LL, Soules ME \& Feldman EL 2009c Sensory neurons and Schwann cells respond to oxidative stress by increasing antioxidant defense mechanisms. Antioxidants \& Redox Signaling 11 425-438. (doi:10.1089/ars.2008.2235)

Vincent AM, Callaghan BC, Smith AL \& Feldman EL 2011 Diabetic neuropathy: cellular mechanisms as therapeutic targets. Nature Reviews. Neurology 7 573-583. (doi:10.1038/nrneurol.2011.137)

Vitadello M, Couraud JY, Hassig R, Gorio A \& Di Giamberardino L 1983 Axonal transport of acetylcholinesterase in the diabetic mutant mouse. Experimental Neurology 82 143-147. (doi:10.1016/00144886(83)90249-2)

Vitadello M, Filliatreau G, Dupont JL, Hassig R, Gorio A \& Di Giamberardino L 1985 Altered axonal transport of cytoskeletal proteins in the mutant diabetic mouse. Journal of Neurochemistry $\mathbf{4 5}$ 860-868. (doi:10.1111/j.1471-4159.1985.tb04073.x)

Vivekanandan-Giri A, Byun J \& Pennathur S 2011 Quantitative analysis of amino acid oxidation markers by tandem mass spectrometry. Methods in Enzymology 491 73-89. (doi:10.1016/B978-0-12-385928-0.00005-5)

Wiggin TD, Kretzler M, Pennathur S, Sullivan KA, Brosius FC \& Feldman EL 2008 Rosiglitazone treatment reduces diabetic neuropathy in streptozotocin-treated DBA/2J mice. Endocrinology 149 4928-4937. (doi:10.1210/en.2008-0869)

Young MJ, Boulton AJ, MacLeod AF, Williams DR \& Sonksen PH 1993 A multicentre study of the prevalence of diabetic peripheral neuropathy in the United Kingdom hospital clinic population. Diabetologia 36 150-154. (doi:10.1007/BF00400697)

Yudkoff M, Nelson D, Daikhin Y \& Erecinska M 1994 Tricarboxylic acid cycle in rat brain synaptosomes. Fluxes and interactions with aspartate aminotransferase and malate/aspartate shuttle. Journal of Biological Chemistry 269 27414-27420.

Zhang L, Yu C, Vasquez FE, Galeva N, Onyango I, Swerdlow RH \& Dobrowsky RT 2010 Hyperglycemia alters the Schwann cell mitochondrial proteome and decreases coupled respiration in the absence of superoxide production. Journal of Proteome Research 9 458-471. (doi:10.1021/pr900818g)

Received in final form 16 October 2012

Accepted 19 October 2012

Accepted Preprint published online 19 October 2012 http://www.joe.endocrinology-journals.org DOI: 10.1530/JOE-12-0356
() 2013 Society for Endocrinology Printed in Great Britain
Published by Bioscientifica Ltd. 